\title{
Local institutions of culture as urban stewards: in pursuit of hybrid governance in Warsaw, Poland
}

Artur Jerzy Filip ${ }^{1}$

\begin{abstract}
Since 2014, several local entrepreneurs and public institutions of culture have collaborated in transforming a central but neglected place in Warsaw, Poland: Plac Defilad (Parade Square), one of the biggest public squares in Europe. These organizations faced the challenge of taking care of their direct environment, even though they had no legal rights to it, and made efforts to get involved in local management, land-use, and place-making politics by establishing informal cross-sectoral partnership agreements. Between 2017 and 2019 the project was further developed under the conceptual framework of urban environmental stewardship as a participatory action research (PAR) program, facilitated by the author of the paper. The primary goal was to examine whether local institutions of culture could play the roles of urban stewards, and, as such, facilitate the process of creating hybrid governance structures. Only partly successful so far, the project can be seen as a precedent for more inclusive urban environmental governance policies in Warsaw. The findings of the paper highlight an underlying lack of legal vehicles and resources that would allow public institutions to form a coalition and become permanently involved in public space planning issues (that is, a contribution to stewardship practices). Furthermore, the paper argues for the need to consider the "concrete" public square an environmental issue, and for the usefulness of the conceptual framework of urban environmental stewardship for developing further research on hybrid governance initiatives in Poland (a contribution to stewardship theory).
\end{abstract}

Key Words: hybrid governance; public institutions of culture; public space; urban stewardship; Warsaw

\section{INTRODUCTION}

Repeated attempts to give citizens as much direct control as possible over shaping their urban environments have been made all over the world for the last half a century with regard to democratic principles (Lefebvre 2012), ideals of locality (Kotler 1969), as a response to economic-social inequalities (Angotti 2010), and as a counter-reaction to ineffective bureaucracies (Lydon and Garcia 2015). At the same time, because the discussion about how cities might be used, planned, and managed reflects a general debate on democratic values, it also emphasizes the role of public institutions as indispensable guarantors of fair treatment for all, competent management, and decision-making processes that are as unantagonistic as possible (Fainstein 2010, Gzell 2010). Therefore, the challenge today is not merely to place bottom-up ambitions in opposition to top-down regimes, for such a perspective is of little cognitive use (Burdett 2014), but rather to further explore how all the urban actors might contribute to one intertwined stewardship structure (Svendsen and Campbell 2008, Fisher et al. 2012, Anderson et al. 2014, Connolly et al. 2014, Romolini et al. 2016, Campbell et al. 2019). And if so, the questions about who might be the stewards and how such urban stewards might play pivotal in-between roles continue to be the most relevant. The primary goal of this paper is therefore to examine whether such a pivotal role within urban environmental stewardship structures might be played specifically by institutions of culture such as museums, galleries, theaters, etc.

There are three reasons to take cultural institutions into consideration. First, with very few exceptions, institutions of culture have their own premises that are inextricably linked with their local surroundings and communities; they are physically and geographically oriented, and as such should be considered essential environmental materialities. The relation between institutions and their environments is mutual: institutions are often planned, designed, and built to contribute to the quality of local environments, while the environmental qualities are expected to enhance both the institutions' operations and public image. Although the precise understanding of "good local environments" differs depending on one's perspective (Williams and Green 2001), institutions have already become critical components of many urban transformations worldwide. This phenomenon, christened the "Bilbao Effect," has gained currency since the opening of the Frank Gehry-designed Guggenheim Museum in Bilbao in 1997. Though they have been much discussed and criticized for their "wow effect" aesthetics (Rybczynski 2002), questionable catalytic role (Grodach 2008), insufficient local benefits (Doucet 2009), and urban transformation narrative defects (Ponzini 2010), Bilbao-like cultural institutions have remained integral parts of many larger and coherent urban policies (Ponzini 2010).

Second, institutions of culture are perceived as desirable allies. An extensive analysis conducted by Elizabeth Strom offers strong arguments in favor of involving these institutions in urban development processes. Simply put, their association with "beauty, good taste, and higher purpose" makes them appealing to citizens, investors, and tourists alike (Strom 2002:7). Even more, their unique public reputation makes any urban project "more palatable to voters and opinion shapers" (Strom 2002:8). On the other hand, Strom argues that it also benefits the institutions to be perceived as drivers of positive urban change. The main reasons for this are increased financial profitability, the potential to attract a wider audience, and greater integration with local communities (Strom 2002). Finally, Strom concludes that such involvement does not necessarily lead cultural institutions to lose their core constituencies (Strom 2002); in many cases, quite the opposite is true. All of these factors make cultural institutions desirable allies for various attempts to redefine and redevelop particular urban environments (Strom 2002). 
Third, today's institutions are eager to become active stakeholders for their own sake. Public involvement has already become a key component in the programs of many modern institutions of culture. The new operating models of progressive museums and performing arts centers, unlike those of their 19th and 20th century predecessors, are built on a desire to get directly involved in everyday issues, to prove their relevance in contemporary life (Simon 2010), with an added emphasis on democratic usership (not monopolized by professionals) of urban environments. The result is that institutions have become ready to seek relations with different users (stakeholders), to build new hierarchies, and to experiment with new collaborative practices (Wright 2014). Today's art institutions aim to be "useful," meaning that they wish to do more than just shed light on problems and voice criticism, but also open up new alternatives never before imagined (Möntmann 2009): making proposals, building structures, negotiating, and even implementing solutions (Byrne et al. 2018). So far, in a few particular cases, institutions of culture volunteered to take the lead in bringing together governments and citizens, even if it required an adaptation to out-of-the-box modes of operation (Carrillo 2017).

To sum up, because (1) institutions of culture, together with their surroundings, are critical elements of urban environment development policies, (2) they are commonly perceived as desirable allies, and (3) they themselves are willing to become active stakeholders, I aim to provide a preliminary assessment of whether these local institutions of culture might play the roles of urban stewards, and, as such, facilitate the process of forming hybrid governance. This hypothesis is examined using the example of a challenge undertaken recently by a couple of institutions of culture in Warsaw, Poland that have engaged over the past few years in collaborative practices with the goal of redeveloping their direct environment, the biggest public space in Warsaw: Plac Defilad (Parade Square).

This paper is an overview and a summary of a two-year-long participatory action research (PAR) project conducted by the author in close cooperation with all the partnering institutions. The enterprise was possible thanks to an assignment given to the author by the Museum of Modern Art in Warsaw, one of the institutions collaborating on the square. In 2017 the author joined the activities, which had begun in 2014, and introduced some hybrid governance benchmarks from the city of New York, while also contributing insight based on urban environmental stewardship theory, relying mainly on publications associated with the U.S. Department of Agriculture New York City Urban Field Station. The urban environmental stewardship model has since been adopted as a theoretical framework and has led to the creation of a joint vision of a desired stewardship structure as well as specific operational goals. The project is not finished yet, though it is advanced enough to take stock of its progress, which this paper attempts to do.

\section{CONCEPTUAL FRAMEWORK: URBAN ENVIRONMENTAL STEWARDSHIP}

Because it has not only been an attempt to develop a collaborative practice within a particular location, but also a general experiment in establishing Poland's first site-specific governance structure, the case presented within this paper required a broad and flexible conceptual framework. The project drew inspiration from New
York City-based benchmarks, but could not be conducted by adhering too rigidly to any specific American participatory vehicle because they had not existed in Poland. Planning culture in Europe is not as open to forming unorthodox arrangements in which private (individual, community, business) agents stand in for public entities (Fishman 2000). On the contrary, in Europe matters involving public space are most often negotiated through public alternative-antagonistic practices (Mouffe 2005, Gualini et al. 2015) with elected authorities typically expected to play a dominant role in forming and managing it in the public interest because of their democratic legitimacy (Newman and Thornley 1996). Openness to civic-led initiatives is even smaller in young postcommunist democracies in Central-Eastern Europe, such as Poland, where civic engagement grows rapidly but remains rather piecemeal, and where local governments reluctantly give away any fields of authority (Czapiński and Panek 2015).

Compared with common but significantly narrower frameworks limited to either community-based endeavors (Peterman 2000), business-run setups (Mitchell 2009), accidental "everyday" civic activities (Chase et al. 1999), and temporary solutions (Overmeyer 2007), the urban environmental stewardship model provides a much more general, all-encompassing perspective within which all individuals, community groups, entrepreneurs, institutions, and government agencies are seen as potential urban environmental stewards (Svendsen and Campbell 2008, Fisher et al. 2012), as long as they assume sustainable responsibility for urban environments (certain geographically defined turfs), even without legal rights to them. Although environmental stewardship studies and publications have so far focused mainly on urban greeneries, i.e., rivers, parks, community gardens, etc., the turfs have been understood broadly as urban environmental materialities, including built structures and designed public spaces (e.g., Colding and Barthel 2013, Svendsen 2013), thus also allowing "concrete" public squares to be considered an environmental stewardship turf (this concern will be discussed later in the article). Therefore, the urban environmental stewardship model seems especially relevant as a conceptual framework for research and practice in this specific case, because in large part of the openness and universalism of this approach.

The myriad characteristics that have been attributed to the notion of urban environmental stewardship have coalesced into a comprehensive description of the phenomenon. In the beginning, within one of the first inquiries into the subject, civic stewards were defined very broadly as community-based urban land managers who took responsibility for a wide variety of land use types without being the owners of the sites on which they worked (Svendsen and Campbell 2008). However, as the research has progressed, the list of characteristics has become more specific, and distinguished such activities as conservancy, management, monitoring, advocacy, and education (Fisher et al. 2012). Even more, in some cases urban stewards were able to go far beyond the listed activities and became involved in decision-making and resource-allocation processes that are typically carried out solely by public agencies (Muñoz-Erickson et al. 2016).

What distinguishes the civic stewards in particular is their willingness and ability to form sustainable cross-sectoral arrangements, to blur formerly clear-cut roles, and thus to develop hybrid governance structures (Svendsen 2010) that make it 
possible to balance social and ecological demands, and hence to monitor and manage complex multiscalar ecosystem services much more comprehensively (Connolly et al. 2014). Such governance structures, however, are possible and operational only under two fundamental conditions. One is a willingness of city agencies to partner with, and even to cede authority to, the stewards (Romolini et al. 2016). The second is the existence of socalled "broker organizations" that are capable of performing a broad range of activities, from site-specific, on-the-ground work up to involvement in policy-making processes at the governmental level. They are the ones who strengthen ties bridging different sectors and interest groups (Connolly et al. 2013).

The specific features of the bridging organizations are centrality (a high number of ties within the network) and betweenness (a measure of importance in connecting otherwise disconnected agents). Such stewards are best informed, respond to changing conditions faster, and usually have the capacity to share resources with others. However, the maintenance of their unique structural positions requires the bridging organizations to remain bimodal, to maintain good relations with both sides while not being identified solely with any of them. This, in turn, forces them to be double-faced, both to partner with and to criticize public agencies or other community groups, as the case may be. Depending on the perspective, such an approach might be praised as flexible or berated as opportunistic; the fact is, however, that a majority of more mature bridging organizations point to such practices as a conscious part of their organizational culture (Connolly et al. 2013). The urban agents that display the qualities mentioned above are best fitted not only to play the roles of civic stewards themselves, but also to support others in counteracting common challenges: lack of resources, weak institutional frameworks, and organizational unsustainability (Svendsen and Campbell 2008, Fisher et al. 2012), as well as to guarantee the sustainable development of the overall hybrid governance structure.

To conclude, the five elements essential to the urban environmental stewardship model are the following: areas of interest (turfs), participants (stewards), their activities, modes of operation, and governance roles. Together with the list of common challenges and the categorization of varying levels of hybrid governance (Svendsen 2010), they make up the conceptual framework of urban environmental stewardship employed within this participatory action research (Table 1).

\section{METHOD: PARTICIPATORY ACTION RESEARCH}

Participatory action research (PAR), although it contradicts some fundamental characteristics of the traditional approach (such as objectivity, linearity, and reproducibility), provides a useful and respectable methodology that makes it possible to examine theories and hypotheses within practical contexts by implementing them for the benefit of the individuals, communities, and organizations being investigated (Pain 2003, 2004, Koshy 2005, Tripp 2005, McIntyre 2008, Macdonald 2012, Torre et al. 2012). Three complementary characteristics of PAR require the following: the object of the research to be a specific situation expected to be improved (Koshy 2005, Macdonald 2012); the participants to be actively involved and to remain key decision makers throughout the whole implementation-research process (Pain 2003, Pain 2004, McIntyre 2008); and the researcher to be directly involved in the situation of inquiry and to remain a resource for the group (Pain 2003, Koshy 2005, McIntyre 2008, Macdonald 2012).

Table 1. Conceptual framework of urban environmental stewardship as employed in this participatory action research.

\begin{tabular}{|c|c|}
\hline Characteristics & Description \\
\hline $\begin{array}{l}\text { Areas of interest } \\
\text { (turfs) }\end{array}$ & Geographically determined environmental materialities \\
\hline $\begin{array}{l}\text { Participants } \\
\text { (stewards) }\end{array}$ & $\begin{array}{l}\text { Individuals, community groups, entrepreneurs, } \\
\text { institutions, government agencies }\end{array}$ \\
\hline Activities & $\begin{array}{l}\text { Conservancy, management, monitoring, advocating } \\
\text { for, educating, decision making, resource allocating }\end{array}$ \\
\hline $\begin{array}{l}\text { Modes of } \\
\text { operation }\end{array}$ & On-the-ground work, strategy planning, policy making \\
\hline $\begin{array}{l}\text { Governance } \\
\text { roles }\end{array}$ & in-centrality, in-betweenness, bimodality \\
\hline Challenges & $\begin{array}{l}\text { Resources, institutional frameworks, organizational } \\
\text { sustainability }\end{array}$ \\
\hline $\begin{array}{l}\text { Degrees of } \\
\text { hybrid } \\
\text { governance }\end{array}$ & $\begin{array}{l}\text { Weak: The precise stewardship role of each party is } \\
\text { unclear. Groups follow separate agendas. Participatory } \\
\text { planning and design exist but there is no formal } \\
\text { mandate to structure or share decision making. Funds } \\
\text { tend not to be shared between groups. The resource } \\
\text { belongs to everyone and no one at the same time. } \\
\text { Moderate: There is clear partnership and leveraging } \\
\text { between groups that tends to be governed by an } \\
\text { informal agreement. Groups function in supportive } \\
\text { roles serving as advisors to each other. There is sense of } \\
\text { a shared responsibility. Joint fundraising and goal- } \\
\text { setting is common. } \\
\text { Strong: Each group shares an equal responsibility and } \\
\text { accountability to the project. There is a formal } \\
\text { agreement that specifies decision making and shared } \\
\text { financial resources. }\end{array}$ \\
\hline
\end{tabular}

Regarding the three abovementioned characteristics, the PAR approach was particularly relevant in the case of the Plac Defilad research where (1) the author was invited to join the ongoing project by one of the stakeholders with the goal of sharing experience, to provide a conceptual framework, and to advance the collaborative process; (2) all the decisions were discussed and agreed upon collectively by the participants, high profile executives representing the institutions of culture located (or to be located in the near future) on Plac Defilad; and (3) the author remained a facilitator of the process, working to serve the partners to their benefit by sharing knowledge, introducing ideas, and managing internal and public meetings.

To guarantee that the research remained responsive to ongoing events and changing conditions, in order to contribute to the process and serve the participants in the first place, the research protocol had not been fixed rigidly (Pain 2003, 2004). It was conducted, however, in a cyclical manner across essential stages mandatory to PAR research (Fig. 1): exploring the context, planning future activities, implementing the plan, reflecting upon the results, and refining the plan (Pain 2003, 2004, Tripp 2005, McIntyre 2008, Macdonald 2012). The two initial and the two final phases were mainly learning oriented, while the middle phase was mainly action oriented, although, in practice, no stage was clear cut (Koshy 2005, Tripp 2005) and the learning process occurred cumulatively throughout (Tripp 2005). 
Fig. 1. Cyclical protocol of the research: exploring the context (reconnaissance), planning future activities, implementing the plan, reflecting upon the results, and refining the plan.

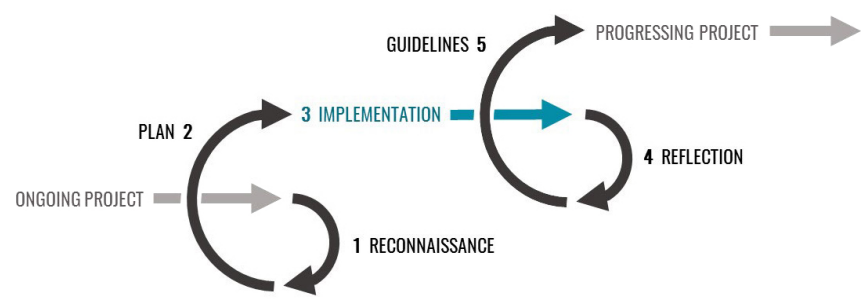

Each particular PAR project is designed using selected qualitative or quantitative research methods to fit a particular object of inquiry (Pain 2003, Koshy 2005, McIntyre 2008). Here, the research met the requirement of data triangulation by combining desk-research (media coverage and documents), interviews (personal testimonies from direct participants) ${ }^{[1]}$, and first-hand observations by the author, who was actively involved in the process. The scope in which particular methods were employed varied across stages:

1. Phases 1-2: To get an optimal picture of the ongoing project, the author conducted individual, unstructured conversations with all the stakeholders actively involved (around 10 people) and desk research of local media coverage, public policy documents, and unpublished internal documents provided by the stakeholders. The acquired knowledge served as a basis for the proposed action plan, which was then verified and augmented by the stakeholders during collective discussion meetings.

2. Phase 3: During the implementation phase, the author coorganized and moderated collective meetings, conducted multiple informal and semiformal conversations with the stakeholders (without any structured agenda), and represented the group in meetings with city officials. Desk research continued for as long as new documents and media publications came out. During this stage, some internal documents were produced and public statements were expressed collectively by the stakeholders themselves (facilitated by the author).

3. Phases 4-5: Research was concluded with a final round of semistructured interviews with five major partners. The interview protocol was based directly on the urban environmental stewardship conceptual framework, thus each interviewee answered five open-ended questions regarding the project's turf (Plac Defilad): (1) Who did you collaborate with? (2) What activities did you undertake jointly? (3) What were your primary modes of operation? (4) What governance role did you and your collaborators play? And (5) What challenges do you and your collaborators face today? At the end, each interviewee selected a degree of hybrid governance that in their opinion best described the result achieved by the stakeholders.
CASE STUDY: LOCAL STEWARDS OF PLAC DEFILAD

Plac Defilad, initially called Stalin's Square upon its completion in 1954, is a monumental square in front of the Palace of Culture and Science, the communist skyscraper raised in the very center of Warsaw in 1955 (Fig. 2). From the very beginning, the only steward of the land was the City (or a municipal corporation tasked with managing the Palace's property, referred to below as the Palace). Thus, by sole virtue of the City's choices, the vast open space has served as a place for political manifestations, religious gatherings, fairs, concerts, commerce, and, most recently, a parking lot and a makeshift bus terminal. Various plans and designs for the square's redevelopment, equally top-down, were undertaken after the political transition in Poland in 1989. The current redevelopment project based on the latest zoning is also being undertaken and managed solely by the City. Until recently, none of the local entrepreneurs and institutions of culture located in the Palace (nor the ones that are to be located in the square in the future) were directly involved in the planning or management process. Furthermore, even these local entities, whenever they wanted to use the square, had to go through complicated bureaucratic procedures (interviews \#2,4). There was also no cooperation among the tenants themselves (interviews \#1, 2, 4).

Around 2014, two local entrepreneurs who ran café-clubs in the Palace's ground level jointly organized the first public events right in front of their own venues without even asking for permission. Shortly thereafter, the City provided financial and organizational support, thanks to which the project developed into an annual festival with one of the local public theaters, the Studio, selected to be the project's official producer, and the Palace pledged to provide technical support. The organizers expressed a strong desire to manage the project jointly using an open format, as a cross-institutional initiative, and organized a few high profile city meetings as well as several operational workshops, which garnered the project a lot of partners from the beginning (interview \#4). Thanks to these efforts, the vision of the place and the program of the festival were developed in a collaborative fashion. However, over the following years, as the project became increasingly professional, the group of partners gradually narrowed, both in terms of physical proximity and ideological affinity, and from then on specific institutional agendas began to play a selective role (interviews \#2, 3, 4). Moreover, apart from the festival, a couple of other public events and initiatives in the square have been developed by all the local institutions, and even if most of them were organized individually, everyday collaboration on both technical and promotional issues has improved significantly over the past few years (interviews \#1, 2, $3,4)$ : "Neighborly relations have been established" (interview \#4).

The noticeable progress in cross-institutional and personal relations was one of the three major achievements that brought the stakeholders closer to a potential stewardship structure. The second achievement was a successful experiment in sharing land management responsibilities. Initially, all of the land around the Palace of Culture was managed solely by the Palace itself. In order to facilitate the organization of the festival, however, a certain area immediately in front of the building was formally handed over to the Studio Theater, which, for the past few years, has been the legal year-round operator of this part of the square. Moreover, as part of a gentleman's agreement, a subpart of this area was 
Fig. 2. A monumental Stalin's Square, later called Plac Defilad (Parade Square) as drawn by the architects in 1954. Until very recently, the sole steward of the vast land around the Palace of Culture and Science was the City (or a municipally owned corporation managing the Palace's property).

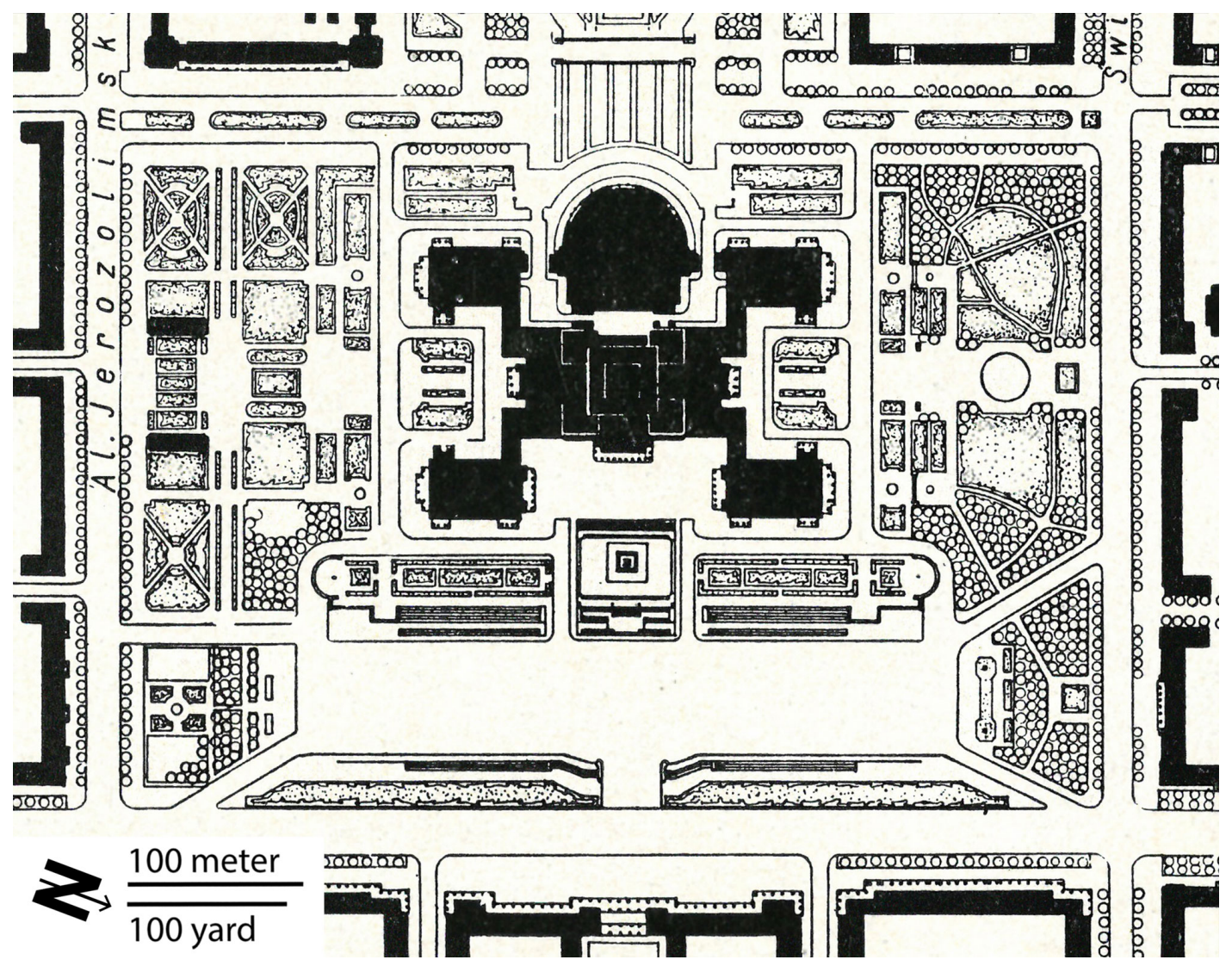

handed over to the Dramatic Theater, which presents annual art installations related to its current program (interviews \#1, 2, 4). This unique arrangement will serve as a strong precedent for future attempts to build a permanent stewardship format for place management. Finally, the third achievement involves the understanding of the cultural institution's scope of responsibilities. After facing public accusations of misappropriation of funds, the Studio Theater and the City have finally developed a legitimate system for transferring money and management responsibilities. Furthermore, the theater proved that, as an art institution, it had a valid claim to be an active public space stakeholder, rather than just an entity whose scope of activity was limited to running an arts program (interview \#4).

The festival was launched and later developed with the clear intent to alter the face of Plac Defilad. The program included temporary rearrangements of the space with urban furniture and greenery, a design competition in which contestant created artistic visions for the future of the square, and some conceptual and research work devoted to Plac Defilad's brand (Plac Defilad. Model marki. [Plac Defilad. Brand model] 2015, unpublished report). Yet the ongoing activities were not focused directly on urban planning or land development issues, and addressed them in a very romanticized way, if at all. Concurrently, however, the City proceeded with implementing its new zoning plan, according to which the square itself was to be reduced in size and several new public buildings were to be built: the Museum of Modern Art in Warsaw and the TR Warsaw theater. This brought three fundamental changes to the ongoing situation. First, the turf was no longer to be the entire surroundings of the Palace, nor its closest vicinity, but a newly designated area between the Palace and the future buildings (with the working name "Central Square"). Second, the set of stakeholders was broadened to include the new museum and the new theater. And third, the development process eventually gained momentum, with preliminary excavations and heavy construction vehicles present on site.

The very idea to redevelop the square had not been particularly contentious, and even initial construction work gained little public attention. However, once the pictures of the new square came to light, they were not well received by the general public. Critics took issue with some of the existing square's repulsive characteristics, such as its depressing scale, unbearable summer heat and wind conditions, to which the new design did not provide any answer. It triggered a serious conflict, which has culminated in the stark alternative between a "concrete desert," as the version presented by the City was disparagingly labeled, and a "lively, green plaza," the desired ideal. In fact, the initial design proposal, offered by the same architect who had worked on the Museum of 
Modern Art building, indiscriminately complied with the existing zoning ordinance, and was focused mainly on architectural aesthetic expression. On the other hand, however, the "green" alternative seemed to have been founded on the naïve belief in a "the greener, the better" approach, with not much attention paid to local necessities, technical conditions, and the broader urban context. In the meantime, even more radical options were discussed, some of which rejected the idea of the square entirely and recommended that the whole area be converted into a dense forest or, on the contrary, that it be developed by rebuilding the prewar tenement houses that had once stood there, not to mention the idea to tear down the Palace of Culture and Science.

As a result, city authorities acceded to public demands for a more participatory planning process expressed by the civic association Miasto jest Nasze, stepped back, and organized an international design competition for the square with activists and executives of some local institutions in the jury, combined with a rich program of public consultations: workshops, discussions, and online surveys. In order to increase the outreach, the City conducted this process in cooperation with the Museum of Modern Art, which at the same time was organizing the ninth edition of its urban festival "Warsaw Under Construction," this time wholly devoted to the current issues surrounding the redevelopment of Plac Defilad. The festival's program included two major exhibits, the construction of a full-scale mockup of the target shape of the square (a structure known as a baugespann), and a rich program of open-air and indoor educational activities.

In June 2017 the author of this paper was invited by the museum to join the curatorial team and was assigned the task of supporting the ongoing partnering activities based on his past experience (Filip 2014, 2018a). The festival became a vehicle for launching the PAR project described here. This way, one of the key parts of the main exhibition was devoted to the possibility of developing what had thus far been a collaboration into a cross-institutional coalition consisting of all the institutions of culture, present and forthcoming, whose doors were to face the new square: the ones who might support the present redevelopment and, eventually, even manage the square itself. Hybrid governance benchmarks from the City of New York together with the urban environmental stewardship conceptual framework were put forward (see Filip $2018 b$ ). And even before the exhibition was publicly opened in October 2017, the idea was presented to and discussed with the potential partners, who were also invited to shape the accompanying program of the festival. The internal discussion on the future cooperation, now under the label of "Local Stewards of Plac Defilad," was once again resumed. All of the partnering institutions acknowledged the cooperation by signing a letter of intent.

The new format made it possible to go beyond the former scope of collaboration, which focused mainly on organizing cultural events and implementing temporary spatial interventions in the square. The group, now officially declared to be interested in participating within the urban planning and design process, was invited by the City to take part in a workshop organized exclusively for them, and afterwards managed to formulate a joint list of design recommendations, thus demonstrating the potential to speak with a single voice (Plac Centralny w opinii Lokalnych Gospodarzy [Central Square in the opinion of the Local Stewards]
2017, unpublished report). A fortiori, faced with a public discussion of increasingly radical proposals, the group avoided the trap of the concrete vs. green dilemma by focusing on professional arguments and seeking a balanced position that allowed for plenty of greenery without rejecting other functional and economic conditions. The primary argument was the fact that a large public park already existed in the immediate vicinity and improving its design and maintenance would be much more to the point than creating a bare semipark, especially given that an underground parking garage was to be built below the square, thus preventing genuine, intense greenery from being planted at ground level. The group called for the square to be seen as an element of a broader urban structure and for the continuity of the urban planning process to be maintained.

The partners maintained a willingness to further collaborate, and so they kept holding meetings, every two months on average, hosted by a different institution each time. They discussed the general vision and possible operational goals of cooperation. With resources provided by the museum, the author together with the museum's lawyer prepared a broad analysis of possible ways to formalize the group, considering the local government's programs, state legislation, and any existing relevant practices (Warszawskie doświadczenia 2018, unpublished report; Scenariusze wspótzarządzania placem 2018, unpublished report). Yet the findings were unsatisfactory. For example, the Associations Act, which provides the overall framework for civil society associations in Poland, does not recognize institutions or businesses as potential members of civic associations. Likewise, municipal programs aimed at promoting cross-sectoral cooperation are also focused primarily on civic organizations and individuals. On the other hand, those programs that provide for institutional involvement, such as Partnerstwa Lokalne (Local Partnerships), are not truly legal vehicles and, in fact, would not serve the group's needs. These conclusions underlined the fundamental problem with matching any of the existing legal frameworks, and thus emphasized the need for out-of-the-box thinking.

In the public statement adopted jointly by the partners, the group argued for functional and aesthetic interdependency between the new public square and the public institutions of culture located, or to be located, in the square in the near future. Based on this premise, the institutions claimed their right to remain active participants in the planning, design, and future land management process. The main goal, as it was thereby rendered, was to develop a sustainable cross-sectoral governance structure for the square, which would include sharing management responsibilities after the square was built (Opis publiczny 2018 press release). The press release, together with the project's description, was made public through a couple of publications in the press (e.g., Filip 2018c). The critical moment came during a public debate in April 2018, at which all the partners jointly set forth their vision of the future square being managed and programmed in a way that was unprecedented by Polish standards, namely, by a public-private alliance, and offered this proposal up for public discussion. The idea itself was received positively, but doubts were raised about whether such an arrangement could threaten the expected democratic character of the public space (see video, Kim są gospodarze placu Defilad [Who are the stewards of Plac Defilad?], https://vimeo.com/264981153.). 
The initiative was not rejected by the City; however, establishing a hybrid governance structure would require much stronger involvement on the part of city representatives. Even though the partners do not expect any top-down, arbitrary determination by city authorities, and they express openness to any half-measures that could play an interim role in seeking the ultimate solution, there is a need to work on these legal possibilities together. Most importantly, however, "we need [their] acceptance of what we're doing, an affirmation, their blessing, in a sense" (interview \#2). In June 2018 the group addressed a formal letter to the city's mayor with an invitation to further strengthen the cross-sectoral collaboration in favor of the square. This request, however, has had no reply. Progress on the issues was further hindered by the change of local government at the turn of 2018 to 2019.

Despite the stalemate, the group remained actively involved in the square's design process. In 2019, two internal meetings were organized in order to boost coordination between all the ongoing activities involving the square: infrastructure works conducted by the City, the sixth edition of the festival organized by the Studio Theater, the beginning of construction on the Museum of Modern Art, and the design process of the future public square. Both meetings were attended by architects working on the square's design; the second meeting was also attended by city representatives. These events proved how necessary such enhanced collaboration was because both meetings provided essential but otherwise inaccessible knowledge on the ongoing issues for all the partners (interviews \#1, 2, 3, 4, 5).

\section{DISCUSSION: LOCAL INSTITUTIONS OF CULTURE AS URBAN STEWARDS}

The Local Stewards of Plac Defilad case has displayed many of the key characteristics of the urban environmental stewardship conceptual framework employed in this participatory action research (see Table 1). Therefore, this paper's hypothesis, namely that local institutions of culture may play the roles of urban environmental stewards, and, as such, facilitate the process of hybrid governance formation, can be seen as partially substantiated. Although it cannot be concluded that, in this particular case, the partnering institutions have reached a significant level of hybrid stewardship collaboration, many important goals of the environmental stewardship structure have indeed been reached.

First and foremost, the turf of the collaboration, Plac Defilad, has changed over time and cannot be determined unequivocally once and for all. Formally, today's square is still a broad area on the east side of the Palace of Culture and Science, and serves as a dominant point of reference for the Palace, which is the manager of the entire terrain (interview \#1). At the same time, the annual art festival has been organized on a relatively small part directly in front of the building, which is a dominant point of reference for the Studio Theater, the festival's producer (interview \#4). Within this PAR project, however, the adopted boundaries corresponded to the current zoning plan and to the design competition guidelines of 2017 , which is a dominant point of reference for the city planning department, the Museum of Modern Art, and the TR Warsaw theater. Furthermore, the museum and the theater are strongly oriented toward the space between their buildings, that is, slightly to the north side of the square (interviews \#3, 5). In the case of the Dramatic Theater, meanwhile, the south side of the Palace (beyond even the formal boundaries of Plac Defilad) is equally important as Plac Defilad on the east side (interview \#2). Therefore, the Plac Defilad turf boundaries, as adopted within this research, are more of a common ground for all the partners, than a single, clear-cut mutual area (Fig. 3).

Similarly to the turf's boundaries, the relations between the partnering institutions have not been explicit either, as they form a complex network of correlations and dependencies. First, the Studio Theater and the Dramatic Theater are the Palace's tenants, while the Museum of Modern Art and the TR Warsaw theater are independent (actually, the Museum also leases some temporary rooms for its investment division and its archives in the Palace). At the same time, the Studio and the Palace organize the art festival together, while the others are just occasional partners; on the other hand, the construction project is a joint investment by the Museum and the TR. In terms of their programs, the Palace is the most business-oriented, the Dramatic Theater defines itself as a traditional theater, while the Studio, the TR, and the museum consider themselves multidisciplinary, progressive art centers. And last but not least, the museum and the TR are still not present on the square (although construction work on the museum started in April 2019) and, as the interviewees notice, the moment when these two institutions open will also mark a new beginning in their partnerships (interviews $\# 1,2,3,4,5)$. Therefore, although all the partners belong to the category of institutions of culture, the partnering dynamics between them are complex, with different partners playing dominant roles depending on the project and the current context of collaboration.

As to the activities, the stewardship group tried to face the challenges of advocacy and education, and to intervene in the decision-making processes, but most of the work was rather project oriented. Indeed, many successful endeavors have been undertaken by the partners working in various partnership configurations, but there was no single event organized by all of them on equal terms. On the other hand, all the projects have complemented each other by rather harmoniously contributing to the Plac Defilad development, with the Local Stewards of Plac Defilad initiative providing a wider perspective (interview \#4). The question also remains whether the Studio will run the art festival independently after the museum and the TR are built and the new boundaries of the square are defined sometime around 2022-2023. In terms of the planning process, the group has held coordination meetings, but these have become less frequent: "We meet less often, but this is where we are at the moment. The capital investments have been launched, and now it's all about carrying them out" (interview \#1). Indeed, since construction work began on the museum, half of the square has been fenced, and is expected to remain so for at least a few years.

Although no comprehensive formula for future hybrid governance has so far been designed and put in place, some critical elements have been independently tested and proven possible. First, the public land has already been administered by one of the institutions of culture, although not yet by the partnership group as a whole. Also, not only urban furniture elements, but even a large-scale installation (the baugespann structure) was already built on the square by an institution of culture, not the City itself; 
Fig. 3. Local institutions have collaborated in transforming Plac Defilad (Parade Square) since 2014. The picture depicts the participants (letters), future developments as provided by the current zoning (grey shapes), and different jurisdictional boundaries (dashed lines).

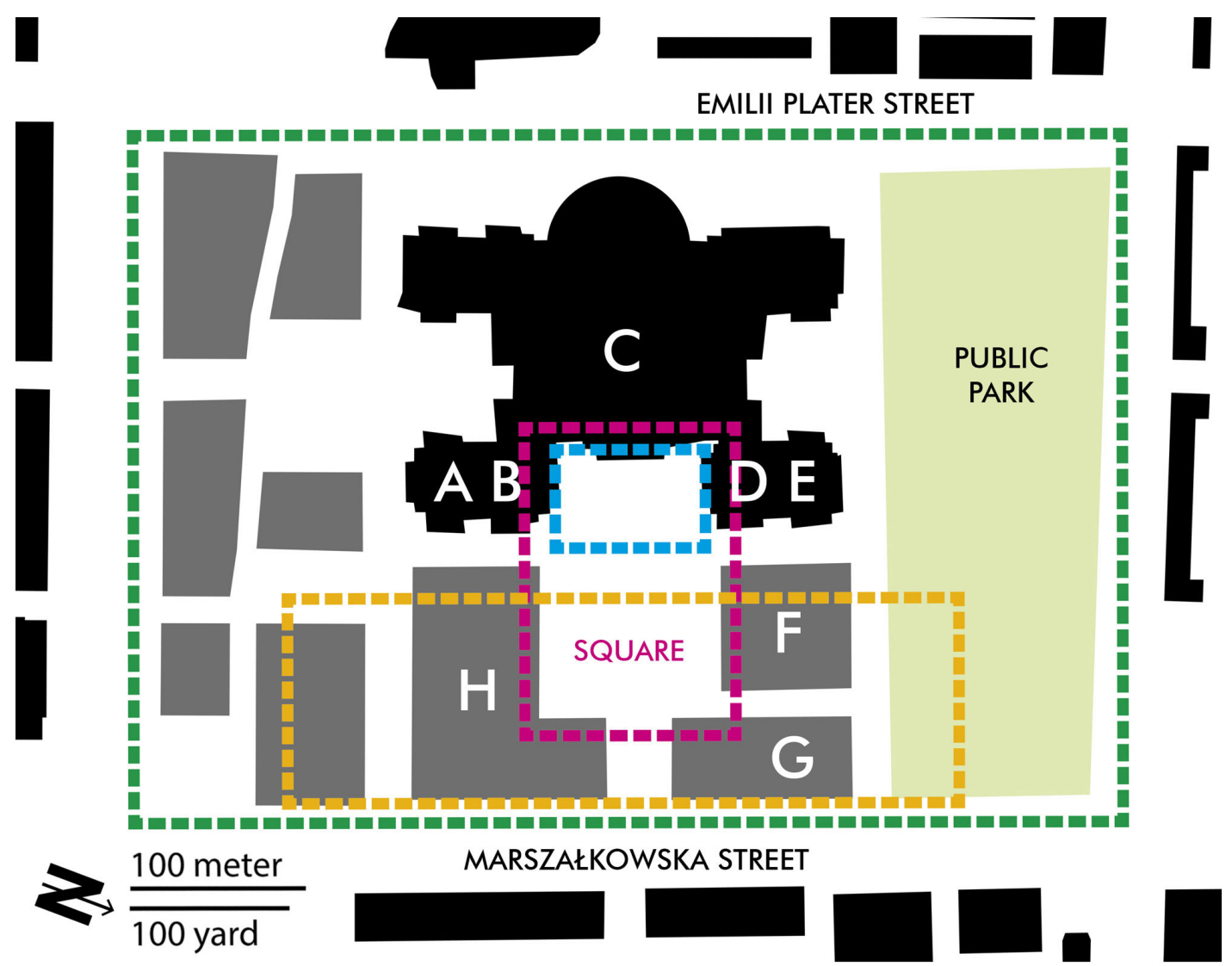
A: Dramatic Theater B: Kulturalna Café
C: Palace of Culture and Science D: BarStudio E: Studio Theater
F: TR Warsaw G: Museum of Modern Art in Warsaw H: tbd
menole area around the Palace, commonly known as Plac Defilad
ma administrative boundaries of today's Plac Defilad
-1." site of Plac Defilad summer art festival
new Plac Defilad (under the working name Central Square)

the project was sponsored by the City, however. And because it is still a challenge for institutions of culture to go beyond their scope of responsibilities, to bear extra costs, and to gain particular expertise, the public battle fought by the Studio and the experience gained by the museum might serve as great precedents. So far, the group has only created an overall vision for future cooperation that awaits the City's answer: "During our meetings we generate ideas that need be implemented by the City" (interview \#2).

By no means has the group played any central role within the overall governance structure: "The political mood is not great for such an experiment. Hierarchical endeavors are favored. The City hasn't reached that level [of cooperation] yet" (interview \#3). The research work done as part of this PAR project in 2018 proved that there is no existing legal vehicle that could be adopted to formalize cooperation among the partners and with the City. In the current situation, however, the partners aim to play at least a bridging role within the governance structure as it exists today, for instance by organizing the informal coordinating meetings with the square's designers and city officials. Their initiatives and projects have also added crucial value to the ongoing developments, especially in terms of public relations. Here, the issue of bimodality has already become crucial: the future role of the Local Stewards, as well as the success of the whole project, seems to be strongly dependent on their ability to stay in-between and to mitigate the concrete vs. green conflict.

The challenges encountered by the partners stem mainly from the fact that the project remains an experiment, and personal good intentions, expressed by representatives of all sides, do not 
necessarily go hand in hand with institutional capabilities and legal conditions. These challenges are lack of funds earmarked for the stewardship role, lack of legal vehicles allowing public institutions to form the coalition, and, therefore, the need to rely on personal relations, which results in institutional unsustainability. There is also no legal vehicle that would enable the formation of a hybrid governance structure together with the City and other potential stakeholders, both civic and business (interviews \#1, 2, 3, 4, 5). Interestingly enough, the operational challenges identified by the partners in Warsaw correspond to those underscored by the American researchers (Svendsen and Campbell 2008, Fisher et al. 2012), which confirms the relevance of the North American framework in the Eastern European context. In this situation, even though soft activities such as developing a joint cultural audience (interview \#5) and coordinating and jointly promoting all the cultural events (interviews $\# 1,2,4,5$ ) are possible, to some extent, through informal agreements, there is an urgent need to envision and implement a legal solution that would make this cross-sectoral collaboration possible at a higher level. And yet, at the same time, the interviewees emphasized their concerns about making such a governance structure too rigid and insufficiently open (interviews \#1, 2, 3): "Maybe someone else would come up with a better idea. The management of the square should be flexible and adaptable to changing conditions and demands" (interview \#2).

The degree of hybrid governance achieved thus far by the stakeholders was described by each of them as a transitional phase between weak and moderate, with an emphasis on the former (interviews \#1, 2, 3, 4, 5). There is a lot of so-called soft collaboration, but with no hard and well-established governance structure. Some elements of partnering relationships have been achieved, but without shared responsibilities and finances. Even knowledge sharing has been only partial (interview \#2). And as for the events on the square, they are organized individually by particular institutions. The partners frankly estimate that the current level of cooperation between them, as well as between them and the City, is unsatisfactory: "There is still not much collaboration on the square; but well... there is no square yet" (interview \#3). For now, the impact of the whole endeavor has mostly been limited to raising awareness, in terms of learning about both institutional and cross-institutional capacities (interview \#5). Nonetheless, "We stirred up a hornet's nest, and there's no turning back now!” (interview \#5).

\section{CONCLUSION}

The Local Stewards of Plac Defilad have not yet achieved their goals. But even though it is by no means certain, because of political, organizational, and personal reasons, how and whether the project will be continued, the initiative has proven its worth as an outstanding attempt undertaken by public institutions of culture to further cross-sectoral collaboration for the maintenance, management, and development of public space. This has been the most advanced endeavor of its kind in Warsaw so far.

The three premises stated in the beginning of the paper, namely that (1) the institutions of culture are concerned about their environments, (2) they are seen as important elements of urban developments, and (3) they are themselves willing to get involved, although validated by the research, proved to be insufficient to develop the desired hybrid governance structure. The lessons learned through the participatory action research undertaken by the institutions of culture in Warsaw point to a fundamental lack of an appropriate legal vehicle. The existing procedures allowing for public participation in Warsaw are not sufficient because they are focused mainly on engaging individuals and not-for-profit civic organizations, while the development of hybrid governance structures requires mechanisms allowing also for entrepreneurs and public institutions to get directly involved. Therefore, this paper indicates a broader need for more inclusive urban planning and management processes in Poland.

The research also indicates the need for the City to see these institutions not only as key elements of the developments, but first and foremost as important, active stakeholders. The amount of energy put into the project by the institutions' leaders so far is the best proof of the high level of readiness on the side of institutions to shape urban environments and public spaces in particular. Nevertheless, there is no chance to further develop hybrid, cross-sectoral collaboration without equal willingness on the part of local government. The city officials' nondisruptive attitude is definitely insufficient. Hybrid governance is not feasible without the city officials' active involvement in shaping legal mechanisms, nor without their willingness to share planning and land management responsibilities. Because of this asymmetry, the partners were limited to strengthening the collaboration among themselves, keeping the cooperation with the City at its existing level, and pursuing informal cooperation with architects and designers. In terms of a broader scope of possible participants of hybrid governance, the activities were limited to making the idea of the collaboration public and discussing it publicly; it was too early to start building sustainable mutual relations with civic organizations or potential business stakeholders.

Furthermore, the research provides the interesting insight that even a literally "concrete" public square should be considered, from the very beginning, as part of the environment, an environmental planning issue. In the case of Plac Defilad, the initial design proposal, which indiscriminately complied with the existing zoning ordinance and was focused mainly on architectural aesthetic expression, had been severely criticized by the general public for being a concrete desert. And only once new ideas had been introduced, among them the most radical ones, did the public debate address the full scope of environmental planning concerns, including such ecological aspects as public space utility and interrelatedness, relation to large-scale green infrastructure, heat and wind conditions, sustainability, cost effectiveness, and governance. In this situation, because the square had come to be considered an element of the broader urban environment, its design became an environmental issue, regardless of how green the square itself would finally be. Interestingly enough, the partnering institutions contributed to this broad environmental perspective by not adopting any single clear-cut and predetermined environmental agenda, which made it possible for the group to assume an intermediary position and to successfully moderate cross-sectoral coordination meetings. Through their design recommendations and numerous public statements, they expressed their willingness to create a welcoming, human-scale space with as much greenery as possible, but also an understanding of other functional and economical aspects, as 
well as the broader urban planning context. They tried to take all the arguments and proposals into account and to move the issue forward by placing emphasis on cooperation and the openness of the planning process, thus enriching and strengthening the overall environmental planning process.

Finally, it should be mentioned that, although a lot of significant accomplishments in terms of developing a hybrid governance structure were achieved before this PAR project had even started, the employment of the urban environmental stewardship conceptual framework has proven its usefulness in, first, describing and evaluating the former experience, and, second, broadening the vision and the scope of partnering activities. In the absence of any ready-to-use legal vehicles in Poland relevant to such initiatives, this conceptual framework allowed the partners to work on the collaboration without being constricted by any rigid formulas established in advance. Also, the initial concern about employing a conceptual framework borrowed from the United States proved to be unsubstantiated, and the paper reaffirms the usefulness of the urban environmental stewardship framework for initiating partnering projects, as well as for developing further research on hybrid governance initiatives in Poland.

${ }^{[1]}$ List of partnering institutions represented by the interviewees: Palace of Culture and Science, 18 June 2019; Dramatic Theater, 25 June 2019; Museum of Modern Art in Warsaw, 9 July 2019; Studio Theater, 26 July 2019; TR Warsaw theater, 20 August 2019.

\section{Responses to this article can be read online at:} http://www.ecologyandsociety.org/issues/responses. $\mathrm{php} / 11512$

\section{Data Availability Statement:}

The data (interviews) that support the findings of this study are available on request from the author. The data are not publicly available because they contain information that could compromise the privacy of research participants.

\section{LITERATURE CITED}

Anderson, E., S. Barthel, S. Borgström, J. Colding, T. Elmqvist, C. Folke, and A. Gren. 2014. Reconnecting cities to the biosphere: stewardship of green infrastructure and urban ecosystem services. Ambio 43:445-453. https://doi.org/10.1007/s13280-014-0506-y

Angotti, T. 2010. Right to the city versus bridging the urban divide. Two separate approaches? Pages 121-123 in A. Venkataraman, editor. Intractable democracy. Fifty years of community-based planning. Pratt Institute, New York, New York, USA.

Burdett, R. 2014. Accretion and rupture in the global city. Pages 32-39 in P. Gadanho, editor. Uneven growth. Tactical urbanisms for expanding megacities. Museum of Modern Art, New York, New York, USA.
Byrne, J., E. Morgan, N. Paynter, A. Sánchez de Serdio, A. Železnik, editors. 2018. The constituent museum. Constellations of knowledge, politics, and mediation. A generator of social change. Valiz, Amsterdam, The Netherlands.

Campbell, L. K., E. Svendsen, N. F. Sonti, S. J. Hines, and D. Maddox. 2019. Green readiness, response, and recovery: a collaborative synthesis. General Technical Report NRS-P-185. U. S. Forest Service, Newtown Square, Pennsylvania, USA. https:// doi.org/10.2737/NRS-GTR-P-185

Carrillo, J. 2017. Conspiratorial institutions? Museums and social transformation in the post-crisis period. $W$ magazine, No. 16. [online] URL: http://wrongwrong.net/artigo/conspiratorialinstitutions-museums-and-social-transformation-in-the-post-crisisperiod

Chase, J., M. Crawford, and J. Kaliski, eds. 1999. Everyday urbanism. Monacelli, New York, New York, USA.

Colding, J., and S. Barthel. 2013. The potential of 'Urban Green Commons' in the resilience building of cities. Ecological Economics 86:156-166. https://doi.org/10.1016/j.ecolecon.2012.10.016

Connolly, J. J. T., E. S. Svendsen, D. R. Fisher, and L. K. Campbell. 2013. Organizing urban ecosystem services through environmental stewardship governance in New York City. Landscape and Urban Planning 109:76-84. https://doi.org/10.1016/j.landurbplan.2012.07.001

Connolly, J. J. T., E. S. Svendsen, D. R. Fisher, and L. K. Campbell. 2014. Networked governance and the management of ecosystem services: the case of urban environmental stewardship in New York City. Ecosystem Services 10:187-194. https://doi. org/10.1016/j.ecoser.2014.08.005

Czapiński, J., and T. Panek, editors. 2015. Social diagnosis 2015. Objective and subjective quality of life in Poland. Quarterly of University of Finance and Management in Warsaw 9(4).

Doucet, B. 2009. Global flagships, local impacts. Proceedings of the Institution of Civil Engineers - Design and Planning 162 (3):101-107. https://doi.org/10.1680/udap.2009.162.3.101

Fainstein, S. 2010. The just city. Cornell University Press, Ithaca, New York, USA.

Filip, A. J. 2014. The linear partnership in action. Pages 66-85 in S. Borkowska and E. Zielinska, editors. Open circuit. Urban crosssector partnerships. Fundacja ResPublica Nowa, Warsaw, Poland.

Filip, A. J. 2018a. Wielkie plany $w$ rękach obywateli. Na koalicyjnym szlaku. Fundacja Nowej Kultury Bęc Zmiana, Warszawa, Poland.

Filip, A. J. 2018b. W czyich rękach? Lokalni gospodarze i postulat hybrydowego współzarządzania placem Defilad. [In whose hands? Local stewards and a call for hybrid governance of Plac Defilad]. Pages 142-159 in T. Fudala, editor. Kto odzyska plac Defilad? Warszawa w Budowie 9? [Who is going to reclaim Plac Defilad?]. Museum of Modern Art in Warsaw, Warsaw, Poland.

Filip, A. J. 2018c. Lokalni gospodarze. [Local stewards]. Builder October:16-17.

Fisher, D. R., L. K. Campbell, and E. S. Svendsen. 2012. The organisational structure of urban environmental stewardship. 
Environmental Politics 21(1):26-48. https://doi.org/10.1080/09644016.2011.643367

Fishman, R., editor. 2000. The American planning tradition. Culture and policy. The Woodrow Wilson Center Press, Washington, D.C., USA.

Grodach, C. 2008. Museums as urban catalysts: the role of urban design in flagship cultural development. Journal of Urban Design 13(2):195-212. https://doi.org/10.1080/13574800801965742

Gualini, E., J. M. Mourato, M. Allegra, editors. 2015. Conflict in the city. Contested urban spaces and local democracy. JOVIS, Berlin, Germany.

Gzell, S. 2010. Reurbanizacja: uwarunkowania. Urbanista, Warsaw, Poland.

Koshy, V. 2005. Action research for improving practice. A practical guide. Paul Chapman, London, UK.

Kotler, M. 1969. Neighborhood government. The local foundations of political life. The Bobbs-Merrill Company, Indianapolis, Illinois, USA.

Lefebvre, H. 2012. Prawo do miasta. Praktyka Teoretyczna 5:183-196. https://doi.org/10.14746/prt.2012.5.14

Lydon, M., and A. Garcia. 2015. Tactical urbanism. Short-term action for long-term change. Island, Washington, D.C., USA. https://doi.org/10.5822/978-1-61091-567-0

Macdonald, C. D. 2012. Understanding participatory action research: a qualitative research methodology option. Canadian Journal of Action Research 13(2):34-50.

McIntyre, A. 2008. Participatory action research. SAGE, Los Angeles, California, USA.

Mitchel, J. 2009. Business improvement districts and the shape of American cities. SUNY Press, New York, New York, USA.

Möntmann, N. 2009. The rise and fall of new institutionalism. Perspectives on a possible future. Pages 155-160 in G. Rauning and G. Ray, editors. Art and contemporary critical practice. Reinventing institutional critique. MayFlyBooks, London, UK.

Mouffe, C. 2005. On the political. Routledge, Abingdon, UK. https://doi.org/10.4324/9780203870112

Muñoz-Erickson, T. A., L. K. Campbell, D. L. Childers, J. M. Grove, D. M. Iwaniec, S. T. A. Picket, M. Romolini, and E. S. Svendsen. 2016. Demystifying governance and its role for transitions in urban social-ecological systems. Ecosphere 7(11): e01564. https://doi.org/10.1002/ecs2.1564

Newman, P., and A. Thornley. 1996. Urban planning in Europe. International competition, national systems and planning projects. Routledge, London, UK. https://doi.org/10.4324/9780203427941

Overmeyer, K. 2007. Urban pioneers: temporary use and urban development in Berlin. Jovis Verlag, Berlin, Germany.

Pain, R. 2003. Social geography: on action-oriented research. Progress in Human Geography 27(5):649-657. https://doi. org/10.1191/0309132503ph455pr
Pain, R. 2004. Social geography: participatory research. Progress in Human Geography 28(5):652-663. https://doi.org/10.1191/0309132504ph511pr

Peterman, W. 2000. Neighborhood planning and community-based development. The potential and limits of grassroots action. SAGE, London, UK.

Ponzini, D. 2010. Bilbao effects and narrative defects. A critical reappraisal of an urban rhetoric. Cahiers de recherche $d u$ Programme Villes \& territoires. Sciences Po, Paris, France.

Romolini, M., J. M. Grove, C. L. Ventriss, C. J. Koliba, and D. H. Krymkowski. 2016. Toward an understanding of citywide urban environmental governance: an examination of stewardship networks in Baltimore and Seattle. Environmental Management 58:254-267. https://doi.org/10.1007/s00267-016-0704-4

Rybczynski, W. 2002. The Bilbao effect. The Atlantic, September issue. [online] URL: http://www.theatlantic.com/issues/2002/09/ rybczynski.htm

Simon, N. 2010. The participatory museum. Museum 2.0, Savannah, Georgia.

Strom, E. 2002. Converting pork into porcelain. Cultural institutions and downtown development. Urban Affairs Review 38(1):3-21. https://doi.org/10.1177/107808702401097763

Svendsen, E. 2010. Civic environmental stewardship as a form of governance in New York City. Dissertation. Columbia University, New York, New York, USA.

Svendsen E. S. 2013. Storyline and design: how civic stewardship shapes urban design in New York City. Pages 269-287 in S. T. A. Pickett, M. L. Cadenasso, and B. McGrath, editors. Resilience in ecology and urban design: linking theory and practice for sustainable cities. Vol. 3. Springer, Dordrecht, The Netherlands. https://doi.org/10.1007/978-94-007-5341-9 13

Svendsen, E. S., and L. K. Campbell. 2008. Urban ecological stewardship: understanding the structure, function and network of community-based urban land management. Cities and the Environment 1(1):4. https://doi.org/10.15365/cate.1142008

Torre, M. E., M. Fine, B. G. Stoudt, and M. Fox. 2012. Critical participatory action research as public science. Pages 171-184 in H. Cooper, P. M. Camic, D. L. Long, A. T. Panter, D. Rindskopf, and K. J. Sher, editors. APA handbooks in psychology. APA handbook of research methods in psychology, Vol. 2. Research designs: quantitative, qualitative, neuropsychological, and biological. American Psychological Association, Washington, D. C., USA. https://doi.org/10.1037/13620-011

Tripp, D. 2005. Action research: a methodological introduction. Educação e Pesquisa 31(3):444-467.

Williams, K., and S. Green. 2001. Literature review of public space and local environments for the cross cutting review. Oxford Centre for Sustainable Development, Oxford, UK. [online] URL: https:// www.academia.edu/4173632/Literature Review of Public Space and Local Environments for the Cross Cutting Review

Wright, S. 2014. Toward a lexicon of usership. Van Abbemuseum, Eindhoven, The Netherlands. 